\title{
Analysis of welded joints using friction stir welding, metal inert gas and tungsten inert gas
}

\section{A.M. KHOURSHID AND IBRAHEEM SABRY}

\begin{abstract}
In this paper, a comprehensive practical study in mechanical properties and cost welding of welded Aluminum 6061 pipe using three different types of welds, Metal Inert Gas (MIG), Tungsten Inert Gas (TIG) and Friction Stir Welding (FSW) with rotation speed (1800 RPM) and travel speed $4 \mathrm{~mm} / \mathrm{min}$. The mechanical properties of the weld have been also investigated using the hardness, elongation and tensile tests. The microstructure of the welds, including the nugget zone and heat affected zone, has been compared with these three methods using optical microscopy and the basis of heat input in weld joint. The results show that FSW improves the mechanical properties of welded joints compare Tungsten Inert Gas (TIG) and Metal Inert Gas (MIG), respectively.
\end{abstract}

KEY WORDS : Friction stir welding (FSW), Metal inert gas (MIG), Tungsten inert gas (TIG), Aluminum alloys

How to cite this Article : Khourshid, A.M. and Sabry, Ibraheem (2016). Analysis of welded joints using friction stir welding, metal inert gas and tungsten inert gas. Engg. \& Tech. in India, 7 (1) : 1-7. 